\title{
Role of Bilirubin and Albumin in Cord Blood as Predictors for Neonatal Hyperbiliru- binemia
}

\author{
Mahmoud Alalfy ${ }^{*}$, Zahraa Mohamed EzzEldin ${ }^{2}$, Yasmeen Amr Mansi², Marwa basher Mostafa ${ }^{3}$, Ahmed \\ Adel $^{4}$ and Ahmed el lithy
}

${ }^{1}$ Lecturer, Researcher, Reproductive health and family planning department, National Research Centre, Egypt, and The senior Fellow in cairo fetal medicine unit, Egypt and Consultant OB/Gyn, Aljazeerah Hospital, Egypt

${ }^{2}$ Professor of Pediatrics \& NeonatologyFaculty of Medicine, Cairo University, Egypt

${ }^{3}$ Specialist of Obstetrics Pediatrics and neonatology, Egypt

${ }^{4}$ Assistant Researcher, Child Health department, National Research Centre, Egypt

${ }^{5}$ Assistant professor Obstetrics and Gynecology, Kasralainy faculty of medicine, Cairo university, Egypt

${ }^{*}$ Corresponding author: Mahmoud Alalfy, PhD. Lecturer, Researcher, Reproductive Health and family planning department, National Research Centre, Egypt, and Consultant OB/Gyn, Aljazeerah Hospital, Egypt, Tel: +201002611058, E-mail: mahmoudalalfy@ymail.com

Citation: Mahmoud Alalfy, Zahraa Mohamed EzzEldin, Yasmeen Amr Mansi, Marwa basher Mostafa, Ahmed Adel, et al. (2018) Role of Bilirubin \& Albumin in Cord Blood as Predictors for Neonatal Hyperbilirubinemia. J Gynecol Res 4(2): 208. doi: 10.15744/2454-3284.4.208

Received Date: August 6, 2018 Accepted Date: September 17, 2018 Published Date: September 18, 2018

\begin{abstract}
Neonatal hyperbilirubinemia is observed during the first week of life in approximately $60 \%$ of term infants and $80 \%$ of preterm infants $[1]$.

Aim of the Work: The aim of this study is to evaluate the predictive value of cord blood bilirubin and albumin in identifying neonates for subsequent hyperbilirubinemia.
\end{abstract}

Patients and Methods: Cord blood samples $(3 \mathrm{ml})$ were collected from all newborns that complied with the protocol inclusion criteria. The samples were sent for the assaying of total, unconjugated, conjugated bilirubin, albumin levels and baby's blood group and rhesus factor.

Results: A cut off level of cord bilirubin/albumin ratio of 0.79 in our study was determined to have $83.3 \%$ sensitivity, $85.7 \%$ specificity and PPV 93.8\% in the prediction of occurrence of significant hyperbilirubinemia in high risk group, with NPV 66.7\%.

Conclusion: We conclude from the results of our study ; that in the total group, the highest sensitivity (83.3\%) was for cut off value of cord bilirubin $(1.88 \mathrm{mg} / \mathrm{dl})$ with PPV $72.9 \%$, which mean that we can predict $83.3 \%$ of patients with the disease (true positives) but $16.7 \%$ of cases with the disease go undetected (false negatives); whilst the highest specificity (84.8\%) was for cut off value of cord bilirubinalbumin(-0.6)with NPV $74.1 \%$,which mean that we can correctly report $84.8 \%$ of patients without the disease as test negative (true negatives) but $15.2 \%$ patients without the disease are incorrectly identified as test positive (false positives).

Keywords: Bilirubin; Albumin; Cord Blood

\section{Introduction}

Neonatal hyperbilirubinemia is observed during the first week of life in approximately $60 \%$ of term infants and $80 \%$ of preterm infants [1].

Hyperbilirubinemia is also the most common cause for readmission during the early neonatal period [2].

Many efforts have been made to identify infants likely to develop neonatal jaundice. Reliable strategies can reduce hospital stay for normal babies and identify significant hyperbilirubinemia that may happen in the future [3].

There have been a few studies which predicted postnatal hyperbilirubinemia by estimating cord blood bilirubin levels but vary in opinions [4-6].

Usually albumin binds with unconjugated bilirubin and protects against kernicterus [7]. 
Thus, different authors have used different cutoff values for predicting significant jaundice. Early detection of risk factors is the first step towards prevention of hyperbilirubinemia and a step ahead in protecting newborns from complication at later age.

\section{Aim of the Work}

The aim of this study is to evaluate the predictive value of cord blood bilirubin and albumin in identifying neonates for subsequent hyperbilirubinemia.

\section{Patients and Methods}

This is a Prospective cohort study that was conducted on 75 neonates, 34 females and 41 males. This study was a multicentric study that was conducted in Kasralainy hospital, National Research Centre, Egypt and Alazhar university hospitals during the period from February 2017 to May 2018.

Inclusion criteria

- Neonates with gestational age 35 weeks or more.

- Any mode of delivery, both genders.

- APGAR score over 7 at the first minute and 10 at fifth minute of life.

- Absence of significant illness or a major congenital malformation.

- Newborns with rhesus D blood group incompatibility are included to be one of the variables in the study as risk factor for hyperbilirubinemia (RH incompatibility).

\section{Exclusion Criteria}

- Significant illness (sepsis, RDS (Respiratory distress syndrome), hypoxia that could aggravate hyperbilirubinemia.

All cases were subjected to:

1- Full history taking with emphasis on the antenatal and perinatal history (maternal illness, maternal drugs, fever), risk factors for hyperbilirubinemia e.g. $\mathrm{ABO}$ or $\mathrm{RH}$ incompatibility.

Individual data from the mothers' medical records e.g. mode of delivery, the cause for Lower segment cesarean section (LSCS), recent \& previous obstetric history, single or multiple pregnancies, past medical history.

2- Full clinical examination immediately after birth.

a. General examination: (vital signs, anthropometric measures, presence of Cephalohaematoma).

b. Systemic examination: (cardiac, abdominal, chest,neurological examination).

c. Gestational age assessment using Ballard score.

3-Clinical and laboratory follow up for level of hyperbilirubinemia.

\section{Laboratory investigation:}

- Cord blood samples $(3 \mathrm{ml})$ were collected from all newborns that complied with the protocol inclusion criteria. The samples were sent for the assaying of total, unconjugated, conjugated bilirubin, albumin levels and baby's blood group and Rhesus factor (Figure 1).

- Method of umbilical cord blood collection: After delivery of the newborn, the umbilical cord was double clamped and transected within 10 seconds. As soon as the newborn was removed from the operative field, cord blood was collected as follows. The placentaside part of the umbilical cord was held straight at a slight angle downward. After identification of a suitable puncture site, the umbilical cord was cleaned, the umbilical vein was then punctured with sterile syring, approximately $3 \mathrm{ml}$ of blood withdrawn from umbilical vein then put in a plain tube to be separated by centrifusion and then the serum tested for albumin \& bilirubin.

- Follow up of babies was done after 72 hrs of age for serum bilirubin (total \& direct) using a peripheral venous sample.

- Bilirubin analyzed by Colorimetric Diazomethod using semiautomated analysis (5010), diazotized sulphanilicacid reaction using Diamond reagent.

- Albumin analyzed by semi-automated SSbromcresol green dye-binding technique using Diamond reagent.

- Babies' blood groups done manually using both anti-A and anti-B sera against the babies' serum and also rhesus D blood group analysis were made manually.

- We used these definitions for our study:

- High risk group: is the group of cases who have RH blood group incompatibility ,also Newborn infants with maternal-fetal ABO incompatibility are at a greater risk for developing subsequent significant hyperbilirubinemia, and therefore ,prediction of probable risk factors, such as the degree of hemolysis, gains importance $[8,9]$.

- Significant hyperbilirubinemia: Serum bilirubin level $\geq 17 \mathrm{mg} / \mathrm{dl}$ after 72 hours of life [10].

- Bilirubin/albumin ratio (B/A) might provide a better estimate of free bilirubin because it contains 2 of the 3 factors determining free bilirubin (TSB, albumin, and the albumin binding affinity). The relationship between free bilirubin and B/A has been studied by titration of serum samples and by measuring free bilirubin in serum of infants with varying B/A,but clinical evidence comparing the relationships of TSB and B/A with outcome is sparse [11]. 


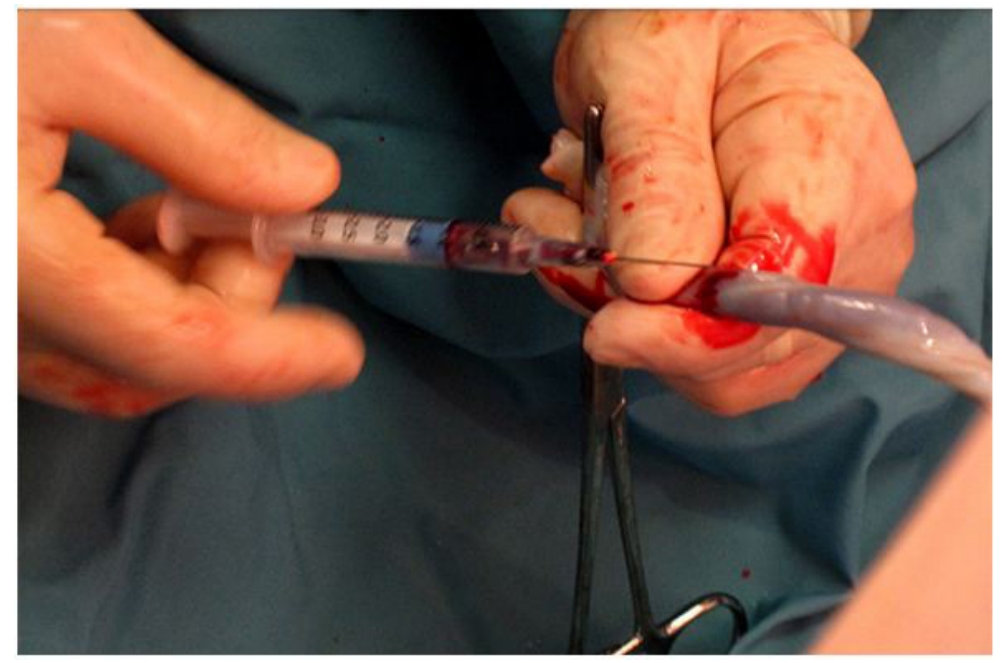

Figure 1: Sampling from cord blood

The statistical methods:

Data were coded and entered using the statistical package SPSS (Statistical Package for the Social Science) version 22. Data was summarized using mean, standard deviation, minimum and maximum in quantitative data and using frequency (count) and relative frequency (percentage) for categorical data.

ROC curve, the sensitivity of a clinical test, the specificity of a clinical test, The positive predictive value (PPV) and The negative predictive value (NPV) [12].

\section{Results}

The present study was conducted on 75 neonates. This study was a multicentric study that was conducted in Kasralainy hospital, National Research Centre, Egypt and Alazhar university hospitals during the period from February 2017 to May 2018.

Our study included 54 fullterm (72\%) \& 21 late preterm (28\%), 41 male (54.7\%) \& 34 female (45.3\%). Forty seven (62.7\%) infants were delivered by (Cesarean section) C/S \& 28 were delivered by NVD (Normal vaginal delivery) (37.3\%).

According to maternal blood group \& Rh: the most common was O (38.7\%) 29 cases, about 66 cases had RH positive (88\%). Table 1 shows demographic distribution, blood groups\& treatment of cases.

\begin{tabular}{|c|c|c|c|}
\hline & & Count & $\%$ \\
\hline \multirow{2}{*}{ Sex } & Male & 41 & $54.7 \%$ \\
\hline & Female & 34 & $45.3 \%$ \\
\hline \multirow{2}{*}{$\begin{array}{l}\text { mode of } \\
\text { delivery }\end{array}$} & $\mathrm{C} / \mathrm{S}$ & 47 & $62.7 \%$ \\
\hline & NVD & 28 & $37.3 \%$ \\
\hline \multirow{4}{*}{$\begin{array}{c}\text { maternal blood } \\
\text { group }\end{array}$} & A & 17 & $22.7 \%$ \\
\hline & B & 15 & $20.0 \%$ \\
\hline & $\mathrm{AB}$ & 14 & $18.7 \%$ \\
\hline & O & 29 & $38.7 \%$ \\
\hline \multirow{2}{*}{ maternal RH } & Positive & 66 & $88.0 \%$ \\
\hline & Negative & 9 & $12.0 \%$ \\
\hline \multirow{4}{*}{$\begin{array}{l}\text { baby blood } \\
\text { group }\end{array}$} & $\mathbf{A}$ & 26 & $34.7 \%$ \\
\hline & B & 26 & $34.7 \%$ \\
\hline & $\mathbf{A B}$ & 11 & $14.7 \%$ \\
\hline & $\mathbf{O}$ & 12 & $16.0 \%$ \\
\hline \multirow{2}{*}{ baby RH } & Positive & 69 & $92.0 \%$ \\
\hline & Negative & 6 & $8.0 \%$ \\
\hline \multirow{3}{*}{ Treatment } & no $\mathrm{ttt}$ & 33 & $44.0 \%$ \\
\hline & Phototherapy & 40 & $53.3 \%$ \\
\hline & exchange transfusion & 2 & $2.7 \%$ \\
\hline
\end{tabular}

Table 1: Demographics, blood groups \& treatment of studied neonates 


\begin{tabular}{|c|c|c|c|c|}
\hline & Mean & Standard Deviation & Minimum & Maximum \\
\hline Weight & 2.87 & \pm .58 & 1.60 & 4.00 \\
\hline gest.age & 37.26 & \pm 4.28 & 35.00 & 41.00 \\
\hline cord total serum bilirubin & 2.13 & \pm .83 & .30 & 4.20 \\
\hline cord direct serum bilirubin & .37 & \pm .27 & .00 & 1.10 \\
\hline cord blood albumin & 2.76 & \pm .71 & 1.30 & 4.70 \\
\hline total serum bilirubin after 72hs of life & 14.68 & \pm 5.33 & 1.20 & 23.00 \\
\hline
\end{tabular}

Table 2 shows that the mean weight of the cases is $2.87 \pm .58 \mathrm{~kg}$. The mean gestational age is $37.26 \pm 4.28$ weeks.

And according to the results of laboratory investigation the mean cord blood total bilirubin is $2.13 \pm .83 \mathrm{mg} / \mathrm{dl}$, mean cord blood albumin is $2.76 \pm .71 \mathrm{~g} / \mathrm{dl}$ and the mean total serum bilirubin after $72 \mathrm{hs}$ of life is $14.68 \pm 5.33 \mathrm{mg} / \mathrm{dl}$.

We have grouped the cases according the level of serum bilirubin done after 72 hours of their life into positive cases who developed significant hyperbilirubinemia (42 cases accounts for 56\%), and negative cases (33 accounts for $44 \%$ of cases).

\begin{tabular}{|c|c|c|c|c|c|c|c|c|}
\hline & & \multicolumn{5}{|c|}{ cord albumin groups } \\
\hline & & cord albumin $<\mathbf{2 . 8} \mathbf{g} / \mathbf{d l}$ & \multicolumn{2}{|c|}{ cord albumin 2.8-3.3 g/dl } & \multicolumn{2}{c|}{ cord albumin $>\mathbf{3 . 3} \mathbf{g} / \mathbf{d l}$} \\
\hline & & Count & $\%$ & Count & $\%$ & Count & $\%$ \\
\hline \multirow{3}{*}{ Hyperbilirubinemia } & positive & 27 & $81.8 \%$ & 15 & $46.9 \%$ & 0 & $.0 \%$ \\
\cline { 2 - 9 } & negative & 6 & $18.2 \%$ & 17 & $53.1 \%$ & 10 & $100.0 \%$ \\
\hline \multirow{2}{*}{ Treatment } & no ttt & 6 & $18.2 \%$ & 17 & $53.1 \%$ & 10 & $100.0 \%$ \\
\cline { 2 - 9 } & phototherapy & 25 & $75.8 \%$ & 15 & $46.9 \%$ & 0 & $.0 \%$ \\
\cline { 2 - 9 } & exchange transfusion & 2 & $6.1 \%$ & 0 & $.0 \%$ & 0 & $.0 \%$ \\
\hline
\end{tabular}

Table 3: The levels of cord blood albumin and the need for intervention

Table 3 show the relation between the level of cord blood albumin and development of significant hyperbilirubinemia (Figure 2) .We categorized the cases into three groups according to their cord albumin level:

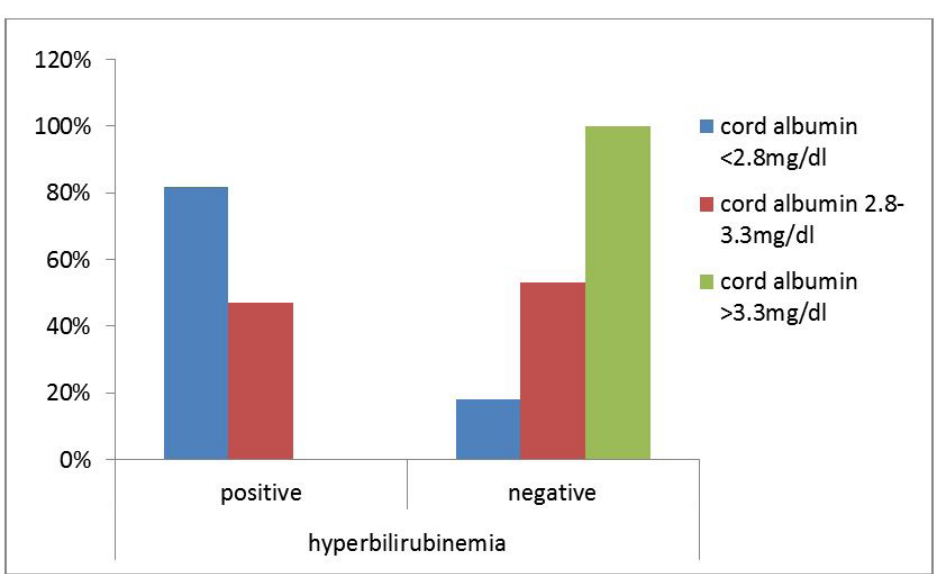

Figure 2: Incidence of significant hyperbilirubinemia in relation to cord blood albumin levels

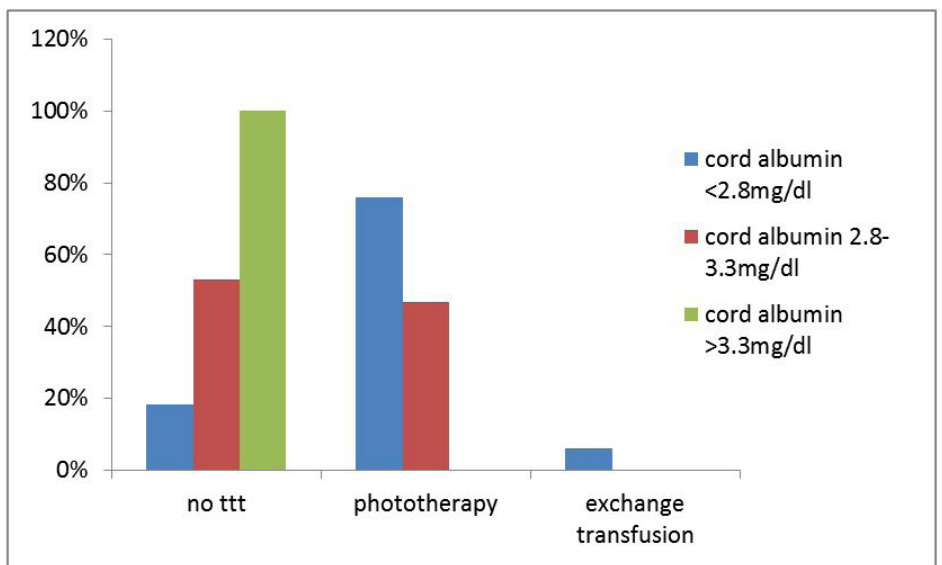

Figure 3: Treatment modalities needed according to levels of cord blood albumin levels 
At cord albumin $<2.8 \mathrm{~g} / \mathrm{dl} \rightarrow 81.8 \%$ of cases (27 cases) developed significant hyperbilirubinemia, with $75.8 \%$ of them (25cases) needing phototherapy and about 6.1\% (2 cases) needing exchange transfusion (Figure 3).

At cord albumin 2.8-3.3 g/dl $\rightarrow 46.9 \%$ of cases (15 cases) developed significant hyperbilirubinemia requiring phototherapy for all them with no need for exchange transfusion (Figure 4).

At cord albumin $>3.3 \mathrm{~g} / \mathrm{dl} \rightarrow$ no cases developed significant hyperbilirubinemia.

\section{ROC Curve}

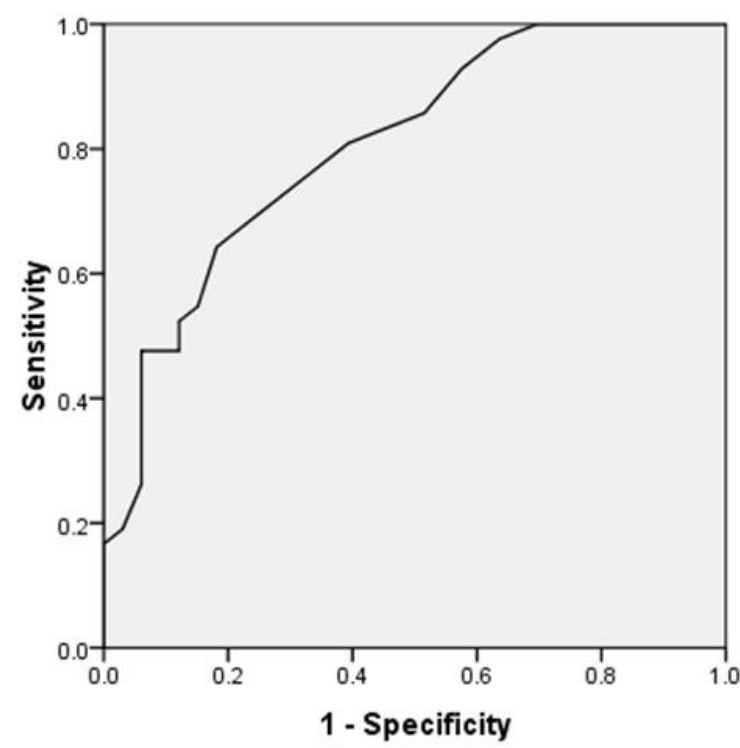

Diagonal segments are produced by ties.

Figure 4: ROC curve showing cord blood albumin sensitivity and specificity in detecting significant hyperbilirubinemia

\begin{tabular}{|c|l|l|l|l|l|l|}
\hline \multirow{2}{*}{ Area under curve } & \multirow{2}{*}{ P value } & \multicolumn{2}{|l|}{ 95\% Confidence Interval } & \multirow{2}{*}{ Cutoff value } & \multirow{2}{*}{ Sensitivity (\%) } & \multirow{2}{*}{ Specificity (\%) } \\
\cline { 3 - 6 } & & Lower Bound & Upper Bound & & & 81.8 \\
\hline
\end{tabular}

Table 4: The sensitivity and specificity of cord blood albumin in detecting significant hyperbilirubinemia

Table 4 shows that a cut-off level of cord blood albumin of $2.75 \mathrm{~g} / \mathrm{dl}$ as obtained by ROC curve was determined to have $64.3 \%$ sensitivity, $81.8 \%$ specificity \& PPV $81.8 \%$ in the prediction of occurrence of significant hyperbilirubinemia.

ROC curve shows that the area under the curve was 0.805 of total area; $\mathrm{p}<0.001$ indicating the usefulness of the test in predicting hyperbilirubinemia (Figure 5).

\section{ROC Curve}

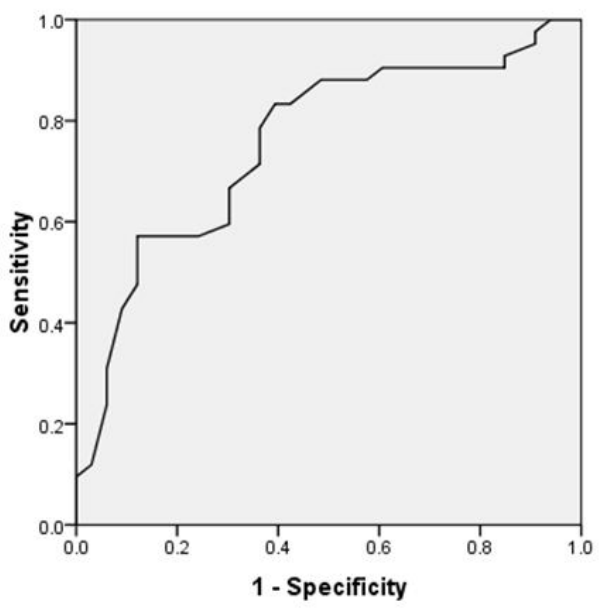

Diagonal segments are produced by ties.

Figure 5: ROC curve showing cord total bilirubin sensitivity and specificity in detecting significant hyperbilirubinemia 
Table 6 shows that a cut-off level of cord blood bilirubin of $1.88 \mathrm{mg} / \mathrm{dl}$ as obtained by ROC curve .It was determined to have $83.3 \%$ sensitivity, $60.6 \%$ specificity \& PPV $72.9 \%$ in the prediction of occurrence of significant hyperbilirubinemia

\begin{tabular}{|c|c|c|c|c|c|c|}
\hline \multirow{2}{*}{ Area under curve } & \multirow{2}{*}{$P$ value } & \multicolumn{2}{|c|}{ 95\% Confidence Interval } & \multirow{2}{*}{ Cutoff value } & \multirow{2}{*}{ Sensitivity (\%) } & \multirow{2}{*}{ Specificity (\%) } \\
\hline & & Lower Bound & Upper Bound & & & \\
\hline .756 & $<0.001$ & .644 & .867 & 1.88 & 83.3 & 60.6 \\
\hline
\end{tabular}

Table 6: The sensitivity and specificity of cord blood total bilirubin in predicting significant hyperbilirubinemia

ROC curve shows that the area under the curve was 0.756 of total area; $p<0.001$ indicating the usefulness of the test in predicting hyperbilirubinemia (Figure 6).

ROC Curve

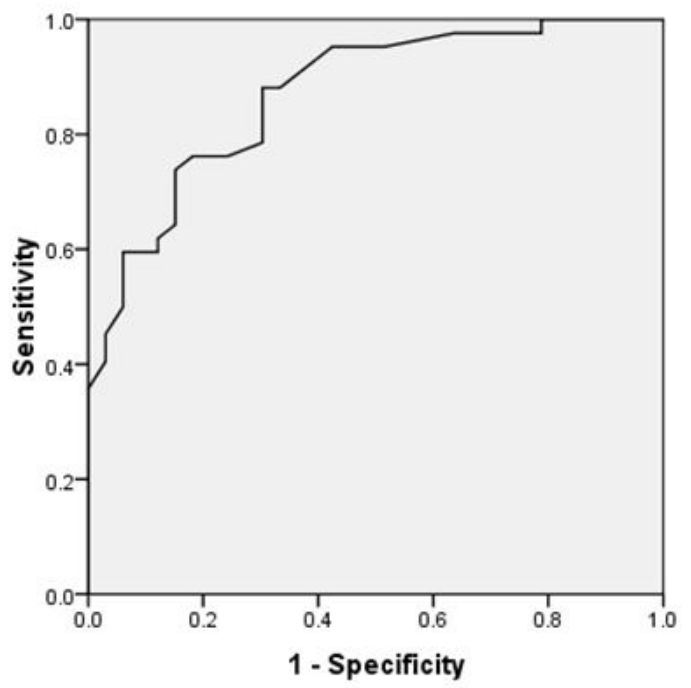

Diagonal segments are produced by ties.

Figure 6: ROC curve showing the sensitivity and specificity of using cord bilirubin - albumin in predicting significant hyperbilirubinemia

Table 7 by using cord bilirubin-albumin to predict significant hyperbilirubinemia we found that a cut-off level of cord blood bilirubin-albumin of -0.6 as obtained by ROC curve was determined to have $73.8 \%$ sensitivity, $84.8 \%$ specificity \& PPV $86.1 \%$ in the prediction of occurrence of significant hyperbilirubinemia Table 8.

ROC curve shows that the area under the curve was 0.870 of total area; $p<0.001$ indicating the usefulness of the test in predicting hyperbilirubinemia (Figure 7).

\section{ROC Curve}

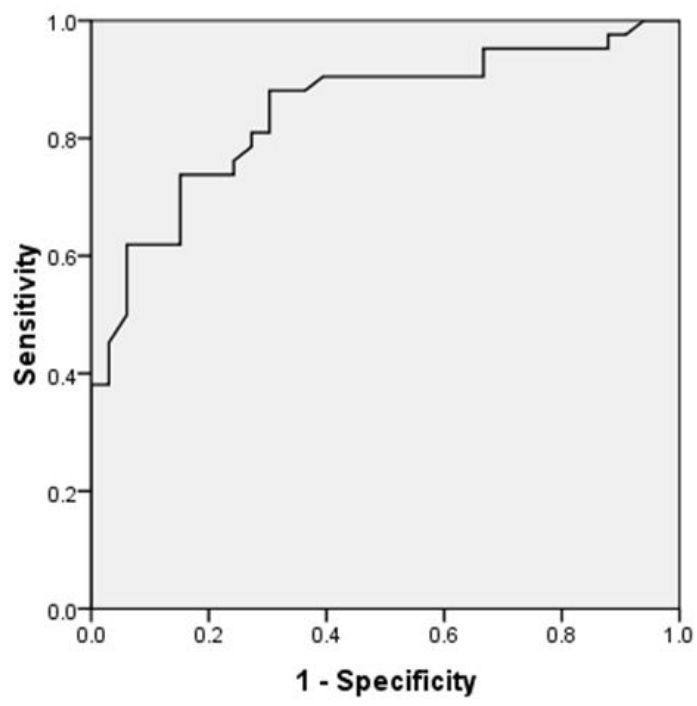

Diagonal segments are produced by ties.

Figure 7: ROCcurve for detection of positive cases using cord bilirubin/cord albumin ratio in all cases 


\begin{tabular}{|c|l|l|l|l|l|l|}
\hline \multirow{2}{*}{ Area under curve } & \multirow{2}{*}{ P value } & \multicolumn{2}{|l|}{ 95\% Confidence Interval } & \multirow{2}{*}{ Cutoff value } & \multirow{2}{*}{ Sensitivity (\%) } & \multirow{2}{*}{ Specificity (\%) } \\
\cline { 3 - 7 } & & Lower Bound & Upper Bound & & & \\
\hline & $<0.001$ & .792 & .949 & -0.6 & 73.8 & 84.8 \\
\hline
\end{tabular}

Table 7: The sensitivity and specificity of using cord bilirubin - albumin in predicting significant hyperbilirubinemia

\begin{tabular}{|c|c|c|c|c|c|}
\hline & Mean & $\begin{array}{c}\text { Standard } \\
\text { Deviation }\end{array}$ & Median & Minimum & Maximum \\
\hline $\begin{array}{c}\text { cord } \\
\text { bilirubin/cord } \\
\text { albumin ratio }\end{array}$ & .84 & .44 & .74 & .08 & 1.92 \\
\hline
\end{tabular}

Table 8: Show mean of bilirubin /albumin ratio in total group

Table 9 shows that a cut off level of cord bilirubin/albumin ratio of 0.78 in our study was determined to have $73.8 \%$ sensitivity, $84.4 \%$ specificity and PPV $86.1 \%$. ROC curve shows that the area under the curve was 0.847 of total area; $\mathrm{p}<0.001$ indicating the usefulness of the test in predicting hyperbilirubinemia.

\begin{tabular}{|c|c|l|l|l|l|l|}
\hline \multirow{2}{*}{ Area under curve } & \multirow{2}{*}{ P value } & \multicolumn{2}{|l|}{ 95\% Confidence Interval } & \multirow{2}{*}{ Cutoff value } & Sensitivity (\%) & \multirow{2}{*}{ Specificity (\%) } \\
\cline { 3 - 5 } & & Lower Bound & Upper Bound & & & \\
\hline .847 & $<0.001$ & .759 & .935 & 0.7876 & 73.8 & 84.8 \\
\hline
\end{tabular}

Table 9: The sensitivity and specificity of using cord bilirubin/cord albumin ratio in predicting significant hyperbilirubinemia in total group

\section{High risk group}

In our study there were 25 neonates at more risk to develop hyperbilirubinemia: 18 cases with ABO incompatibility and 7 cases with $\mathrm{RH}$ incompatibility. Within the ABO group 12 cases (66.6\%) developed significant hyperbilirubinemia, while in $\mathrm{RH}$ group about 5 cases (71.4\%) developed significant hyperbilirubinemia (Figure 8).

\section{ROC Curve}

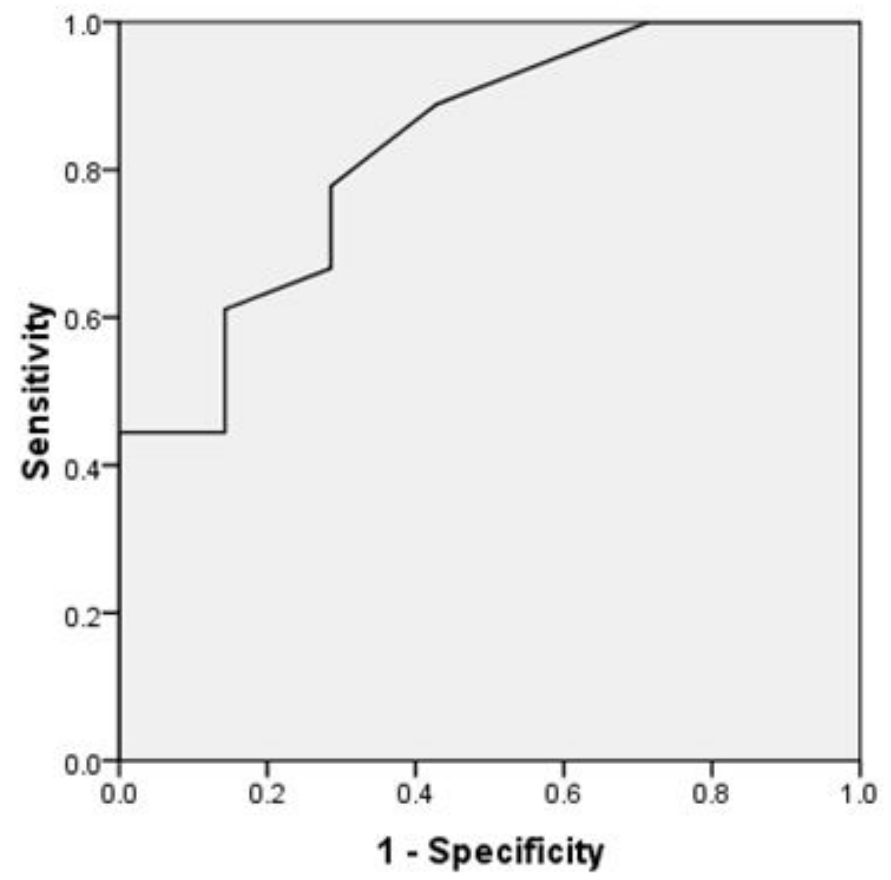

Diagonal segments are produced by ties.

Figure 8: ROCcurve for detection of positive cases using cord bilirubin/cord albumin ratio in all cases

Table 10 shows that among this group males represented about $48 \%$ of cases, $64 \%$ need phototherapy, while $8 \%$ needed exchange transfusion. According to maternal blood group the most common was O (92\%), and between neonates the most common blood group was A (52\%). 


\begin{tabular}{|c|c|c|c|}
\hline & & Count & $\%$ \\
\hline \multirow{2}{*}{ Sex } & Male & 12 & $48.0 \%$ \\
\hline & Female & 13 & $52.0 \%$ \\
\hline \multirow{2}{*}{ mode of delivery } & $\mathrm{C} / \mathrm{S}$ & 17 & $68.0 \%$ \\
\hline & NVD & 8 & $32.0 \%$ \\
\hline \multirow{4}{*}{$\begin{array}{l}\text { maternal blood } \\
\text { group }\end{array}$} & A & 2 & $8.0 \%$ \\
\hline & B & 0 & $.0 \%$ \\
\hline & $A B$ & 0 & $.0 \%$ \\
\hline & O & 23 & $92.0 \%$ \\
\hline \multirow{2}{*}{ maternal RH } & Positive & 18 & $72.0 \%$ \\
\hline & Negative & 7 & $28.0 \%$ \\
\hline \multirow{4}{*}{ baby blood group } & A & 13 & $52.0 \%$ \\
\hline & B & 10 & $40.0 \%$ \\
\hline & $A B$ & 2 & $8.0 \%$ \\
\hline & $\mathbf{O}$ & 0 & $.0 \%$ \\
\hline \multirow{2}{*}{ baby RH } & Positive & 24 & $96.0 \%$ \\
\hline & Negative & 1 & $4.0 \%$ \\
\hline \multirow[t]{3}{*}{ Treatment } & no ttt & 7 & $28.0 \%$ \\
\hline & Phototherapy & 16 & $64.0 \%$ \\
\hline & $\begin{array}{l}\text { exchange } \\
\text { transfusion }\end{array}$ & 2 & $8.0 \%$ \\
\hline
\end{tabular}

Table 10: Demographics .blood groups \& treatment of the high risk group

Table 11 shows that the mean cord blood total bilirubin is $2.52 \mathrm{mg} / \mathrm{dl} \pm .80$, mean cord blood albumin is $2.69 \mathrm{~g} / \mathrm{dl} \pm .82$ and the mean total serum bilirubin after $72 \mathrm{hs}$ of life is $16.76 \mathrm{mg} / \mathrm{dl} \pm 4.18$.

\begin{tabular}{|c|c|c|c|c|c|}
\hline & Mean & Standard Deviation & Median & Minimum & Maximum \\
\hline Weight & 2.84 & \pm .55 & 3.00 & 1.90 & 3.90 \\
\hline gest.age & 37.88 & \pm 1.83 & 38.00 & 35.00 & 40.00 \\
\hline $\begin{array}{c}\text { cord total serum } \\
\text { bilirubin }\end{array}$ & 2.52 & \pm .80 & 2.70 & .90 & 4.20 \\
\hline $\begin{array}{c}\text { cord direct serum } \\
\text { bilirubin }\end{array}$ & .45 & \pm .30 & .50 & .00 & 1.10 \\
\hline $\begin{array}{c}\text { cord blood } \\
\text { albumin }\end{array}$ & 2.69 & \pm .82 & 2.80 & 1.30 & 4.70 \\
\hline $\begin{array}{c}\text { total serum } \\
\text { bilirubin after } \\
\text { 72hs of life }\end{array}$ & 16.76 & \pm 4.18 & 18.20 & 5.00 & 23.00 \\
\hline
\end{tabular}

Table 11: The demographic \& laboratory results of the high risk group

Table 12 that a cut-off level of cord blood albumin of $3 \mathrm{mg} / \mathrm{dl}$ as obtained by ROC curve was determined to have $77.8 \%$ sensitivity, 71.4\% specificity \& PPV $87.5 \%$ in the prediction of the occurrence of significant hyperbilirubinemia

ROC curve shows that the area under the curve was 0.829 of total area; $\mathrm{p} 0.012$ indicating the usefulness of the test in predicting hyperbilirubinemia (Figure 9).

\begin{tabular}{|c|c|l|l|l|l|l|}
\hline \multirow{2}{*}{ Area under curve } & \multirow{2}{*}{ P value } & \multicolumn{2}{|l|}{ 95\% Confidence Interval } & \multirow{2}{*}{ Cutoff value } & \multirow{2}{*}{ Sensitivity (\%) } & \multirow{2}{*}{ Specificity (\%) } \\
\cline { 3 - 6 } & & Lower Bound & Upper Bound & & & \\
\hline .829 & .012 & .652 & 1.006 & 3 & 77.8 & 71.4 \\
\hline
\end{tabular}

Table 12: The sensitivity and specificity of cord blood albumin in detecting significant hyperbilirubinemia in group at risk for $\mathrm{ABO} \& \mathrm{RH}$ incompatibility 


\section{ROC Curve}

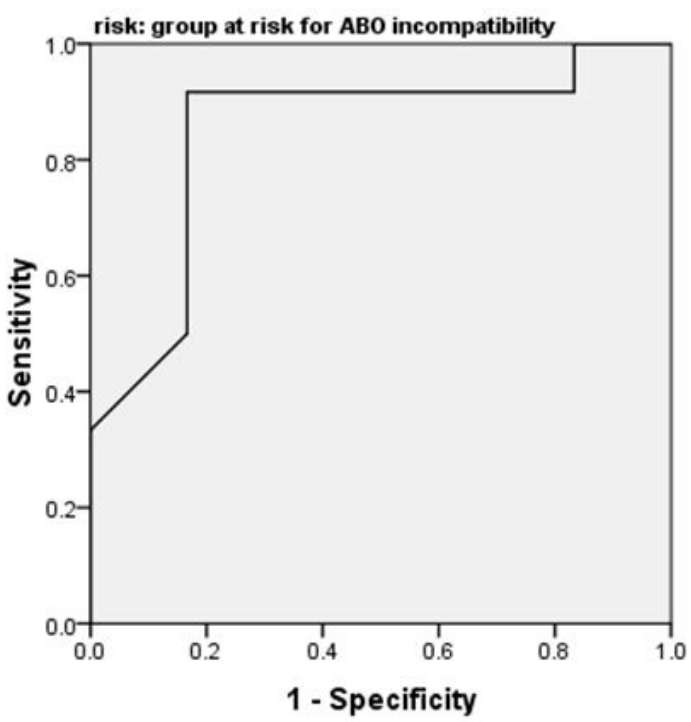

Diagonal segments are produced by ties.

Figure 9: ROC curve showing cord total bilirubin sensitivity and specificity in detecting significant hyperbilirubinemia in group at risk for $\mathrm{ABO} \& \mathrm{RH}$ incompatibility

ROC curve shows that the area under the curve was 0.798 of total area; $\mathrm{p} 0.023$ indicating the usefulness of the test in predicting hyperbilirubinemia (Figure 10).

Table 13 shows that a cut-off level of cord blood bilirubin of $2.48 \mathrm{mg} / \mathrm{dl}$ as obtained by ROC curve was determined to have $72.2 \%$ sensitivity, $85.7 \%$ specificity \& PPV $92.9 \%$ in the prediction of occurrence of significant hyperbilirubinemia.

\begin{tabular}{|c|c|l|l|l|l|l|}
\hline \multirow{2}{*}{ Area under curve } & \multirow{2}{*}{ P value } & \multicolumn{2}{|l|}{ 95\% Confidence Interval } & \multirow{2}{*}{ Cutoff value } & Sensitivity (\%) & \multirow{2}{*}{ Specificity (\%) } \\
\cline { 3 - 6 } & & Lower Bound & Upper Bound & & & \\
\hline .798 & .023 & .596 & .999 & 2.45 & 72.2 & 85.7 \\
\hline
\end{tabular}

Table 13: The sensitivity and specificity of cord blood total bilirubin in predicting significant hyperbilirubinemia in group at risk for $\mathrm{ABO} \& \mathrm{RH}$ incompatibility

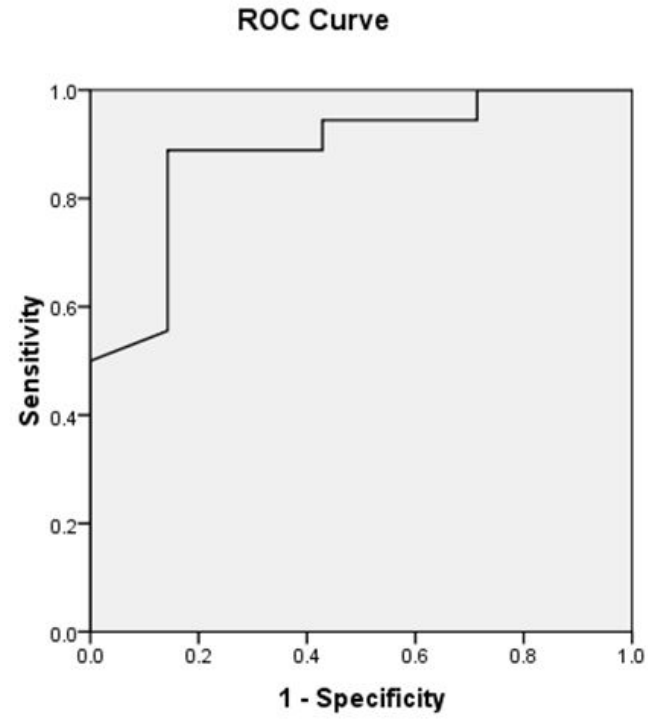

Diagonal segments are produced by ties.

Figure 10: ROC curve showing the sensitivity and specificity of using cord bilirubin - cord albumin in predicting significant hyperbilirubinemia in group at risk for $\mathrm{ABO} \& \mathrm{RH}$ incompatibility 
Table 14 by using cord bilirubin - cord albumin to predict significant hyperbilirubinemia we found that a cut-off level of cord blood bilirubin-albumin of -0.82 as obtained by ROC curve was determined to have $88.9 \%$ sensitivity, $85.7 \%$ specificity \& PPV $94.1 \%$ in the prediction of occurrence of significant hyperbilirubinemia.

ROC curve shows that the area under the curve was 0.885 of total area; p value 0.03 indicating the usefulness of the test in predicting hyperbilirubinemia (Figure 11).

\begin{tabular}{|c|c|l|l|l|l|l|}
\hline \multirow{2}{*}{ Area under curve } & \multirow{2}{*}{ P value } & \multicolumn{2}{|l|}{ 95\% Confidence Interval } & \multirow{2}{*}{ Cutoff value } & Sensitivity (\%) & \multirow{2}{*}{ Specificity (\%) } \\
\cline { 3 - 6 } & & Lower Bound & Upper Bound & & \\
\hline .885 & .003 & .740 & 1.030 & -0.82 & 88.9 & 85.7 \\
\hline
\end{tabular}
hyperbilirubinemia in group at risk for $\mathrm{ABO} \& \mathrm{RH}$ incompatibility

\section{ROC Curve}

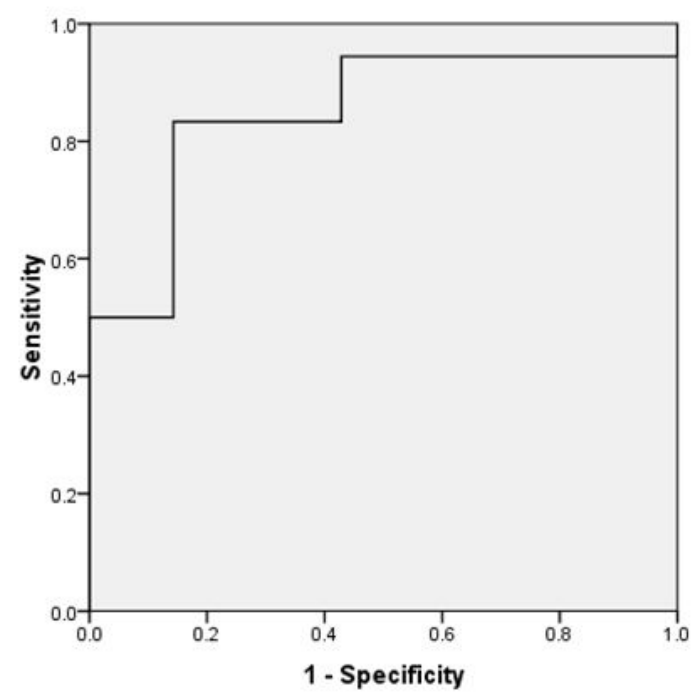

Figure 11: ROC curve for detection of positive cases using cord bilirubin/cord albumin ratio in high risk group

\begin{tabular}{|c|l|l|l|l|l|}
\hline & Mean & $\begin{array}{l}\text { Standard } \\
\text { Deviation }\end{array}$ & Median & Maximum & Maximum \\
\hline $\begin{array}{c}\text { cord } \\
\text { bilirubin/cord } \\
\text { albumin ratio }\end{array}$ & 1.06 & .51 & 1.00 & .30 & 1.92 \\
\hline
\end{tabular}

Table 15: Show mean of cord bilirubin /albumin ratio in high risk group

Table 16 show that a cut off level of cord bilirubin/albumin ratio of 0.79 in our study was determined to have $83.3 \%$ sensitivity, $85.7 \%$ specificity and PPV $93.8 \%$. ROC curve shows that the area under the curve was 0.849 of total area; $p$ value 0.008 indicating the usefulness of the test in predicting hyperbilirubinemia.

\begin{tabular}{|c|c|l|l|l|l|l|}
\hline \multirow{2}{*}{ Area under curve } & \multirow{2}{*}{ P value } & \multicolumn{2}{|l|}{ 95\% Confidence Interval } & \multirow{2}{*}{ Cutoff value } & Sensitivity (\%) & \multirow{2}{*}{ Specificity (\%) } \\
\cline { 3 - 6 } & & Lower Bound & Upper Bound & & & \\
\hline .849 & 0.008 & .686 & 1.012 & 0.7947 & 83.3 & 85.7 \\
\hline
\end{tabular}

Table 16: The sensitivity and specificity of using cord bilirubin/cord albumin ratio in predicting significant hyperbilirubinemia in high risk group

\section{Discussion}

About $50 \%$ of term and $80 \%$ of preterm newborns develop hyperbilirubinemia, which usually appears $2-4$ days after birth, and resolves spontaneously after 1-2 wks [13].

Because of the increasing number of early discharged newborns, there is a corresponding danger of failing to diagnose severe hyperbilirubinemia in time, as reports about kernicterus in full-term healthy newborns demonstrate. [14]. 
In Egypt, it is common that infants are discharged at less than 24 hours of age with little or no evaluation for the risk of developing jaundice or any instructions for follow-up. In fact, clinical or laboratory assessment of jaundice was almost nonexistent even among those who were discharged after the second day of life [15].

In the era of "early discharge", in order not to fail to diagnose significant hyperbilirubinemia and start treatment on time, predicting newborns at high risk of developing hyperbilirubinemia was required.

The aim of our study was to assess whether levels of cord blood albumin and bilirubin at birth could be indicative for development of significant hyperbilirubinemia in neonates $\geq 35$ weeks gestation.

We conducted this prospective cohort study on 75 neonates $\geq 35$ week's gestation, delivered at Kasr al Ainy Hospital during the period from February 2017 to January 2018.

Cord blood samples $(3 \mathrm{ml})$ were collected from all newborns that complied with the protocol inclusion criteria. The samples were sent for the assaying of total, unconjugated, conjugated bilirubin, albumin levels and baby's blood group and rhesus. Follow up of babies was done after $72 \mathrm{hrs}$ of age for serum bilirubin (total \& direct) using a venous sample.

The mean gestational age of our study population was $37.26 \pm 4.28$ wks. Their mean birth weight was $2.87 \pm 0.58 \mathrm{~kg}$. We found significant hyperbilirubinemia in 42 cases (56\%); forty infants (53.3\%) underwent phototherapy; 2 infants underwent exchange transfusion $(2.7 \%)$ and $33(44 \%)$ needed no intervention at all.

We report a quite high incidence of significant hyperbilirubinemia in our study. This high incidence is similar to previous studies in Egypt from 34\%, up to a $54.3 \%$ [16].

Many other studies have reported a lower incidence, Bhutani et al in 2000 (5-6\%) [17]. (9.5\%), (11.5\%), Bernaldo and Segre in $2004(19.86 \%)$, and $(33.8 \%)$ [8,10]. This difference may be attributed to the differences in racial and ethnic groups in different populations studied for jaundice.

It is stated clearly by several authors that male infants are more at risk of developing severe jaundice than their female counterparts These findings do not coincide with our study where we found no significant difference between the male and female distribution of our cases $[8,18]$.

According the levels of cord blood albumin, we found that at cord albumin levels $<2.8 \mathrm{~g} / \mathrm{dl} \rightarrow 81.8 \%$ of cases (27 cases) developed significant hyperbilirubinemia. At cord albumin 2.8-3.3 g/dl $\rightarrow 46.9 \%$ of cases developed significant hyperbilirubinemia, while with levels $>3.3 \mathrm{~g} / \mathrm{dl}$ was considered safe with no incidence of hyperbilirubinemia.

Our study results are similar to many other studies: where at CSA levels $<2.8 \mathrm{~g} / \mathrm{dl}, 58.35 \%$, 95\%, of newborns developed significant hyperbilirubinemia In all of the aforementioned studies at levels $>3.3 \mathrm{~g} / \mathrm{dl}$, no infants developed hyperbilirubinemia. However in the study by Trivedi et al; $12.68 \%$ developed hyperbilirubinemia at CSA $>3.5 \mathrm{~g} / \mathrm{dl}[8,10]$.

We performed a ROC curve analysis to find a cut-off point level of cord blood albumin for development of significant hyperbilirubinemia. It was $2.75 \mathrm{~g} / \mathrm{dl}$; with a low sensitivity $(64.3 \%), 81.8 \%$ specificity, PPV $81.8 \%$ and NPV $64.3 \%$.

According to our study protocol, we further investigated the level of cord blood total bilirubin in our sample. The mean value was $2.13 \pm 0.83 \mathrm{mg} / \mathrm{dl}$. This is near the results found by a previous study which was $2.38 \pm 0.5 \mathrm{mg} / \mathrm{dl}$ [17].

However, other studies found a higher mean cord bilirubin as $2.7 \pm 0.3 \mathrm{mg} / \mathrm{dl}$ and $3.7 \pm 1.07 \mathrm{mg} / \mathrm{dl}[19,20]$. This higher level may be due to the higher mean gestational age in their study group 39.9 weeks versus $37.26 \pm 4.2$ weeks in our study.

With Receiver operating characteristic curve (ROC) analysis, a cord bilirubin level of $1.88 \mathrm{mg} / \mathrm{dl}$ was determined to have $83.3 \%$ sensitivity and $60.6 \%$ specificity. At this critical cord bilirubin level, the negative predictive value was $74.1 \%$ and the positive predictive value was $72.9 \%$.

Cord bilirubin could be a useful predictor for subsequent neonatal jaundice [21]. reported a cut off value of $1.74 \mathrm{mg} / \mathrm{dl}$. However , higher cut off values ranging between $2 \mathrm{mg} / \mathrm{dl}$ up to $2.7 \mathrm{mg} / \mathrm{dl}$ were found in other studies.This may be due to the characters of different studied groups; the cases were all full term infants, $(2 \mathrm{mg} / \mathrm{dl})(2.54 \mathrm{mg} / \mathrm{dl})$; whilst those in our study group consisted of late preterms \& full terms, or having risk factors of ABO or RH incompatibility as in, $(2.1 \mathrm{mg} / \mathrm{dl}$,with $50 \%$ sensitivity\% $97 \%$ specificity), (2mg/dl) \& Ipek et al., (2.6mg/dl,with 50\% sensitivity \& 97\% specificity, PPV 41.1\% \& NPV 97.9\%) [8,15,17,20,22]. In the study group of [23]. $(2.73 \mathrm{mg} / \mathrm{dl}$,with $100 \%$ sensitivity \& $90 \%$ specificity) there is $71.4 \%$ of males developed significant hyperbilirubinemia.

Despite the majority of the studies confirming the usefulness of cord bilirubin in predicting the development of hyperbilirubinemia. It was concluded from a previous study that CB level of $2.2 \mathrm{mg} / \mathrm{dl}$ showed scant sensitivity (22.2\%) but a high negative predictive value (97.4\%) which excluded CB as a useful predictor of subsequent neonatal jaundice [24]. whist another study carried out by Rostami and Mehrabi in 2005 concluded that assessment of cord bilirubin level could not help identify newborns with neonatal hyperbilirubinemia [3]. 
In an attempt to obtain a test with higher sensitivity and specificity than either the cord albumin or bilirubin alone, we decided to use them in combination. Hence, we are the first study to use cord bilirubin-albumin and cord blood bilirubin/ albumin ratio.

We found that a cut-off level of cord blood bilirubin-albumin of -0.6, as obtained by ROC curve analysis, was determined to have $73.8 \%$ sensitivity, $84.8 \%$ specificity \& PPV $86.1 \%$ in the prediction of occurrence of significant hyperbilirubinemia in total group.

Moreover, ROC analysis for bilirubin/albumin ratio in the total group a cut off value of 0.78 with identical sensitivity and specificity PPV and NPV to bilirubin-albumin.

To our knowledge, this is the first study to investigate these 2 parameters, we think they are useful because they have a higher specificity and PPV and NPV than either the bilirubin or albumin cut off levels used separately.

In this study there are 25 cases(33.3\%) were considered at high risk for development of significant hyperbilirubinemia due to they have $\mathrm{ABO}$ or $\mathrm{RH}$ blood group incompatibility with their mothers .

Amongst, our high risk group infants, 2 cases required exchange transfusion : one of them is female,2.5kg, $\pm 38 \mathrm{weeks}, \mathrm{C} / \mathrm{S}$, her blood group B+ve \& maternal blood group O-ve .Her cord bilirubin level was $3 \mathrm{mg} / \mathrm{dl}$, cord albumin level was was1.9g/dl, serum total bilirubin after $72 \mathrm{hrs}$ was $23 \mathrm{mg} / \mathrm{dl}$, retics $5.5 \%$ \& coombs +ve. The second case was male, $1.9 \mathrm{~kg}$, $\pm 35 \mathrm{weeks}$, Delivered by Cesarean section (C/S), his blood group is A+ve \& maternal blood group is $\mathrm{O}+\mathrm{ve}$, cord bilirubin level was $2.5 \mathrm{mg} / \mathrm{dl}$, cord albumin level was $1.3 \mathrm{~g} / \mathrm{dl} \&$ serum total bilirubin after $72 \mathrm{hrs}$ was $21 \mathrm{mg} / \mathrm{dl}$,retics $8 \%$ \& coombs +ve.

According to cord blood albumin level in high risk group, using ROC curve analysis we found that the cut off level of cord blood albumin of $3 \mathrm{~g} / \mathrm{dl}$, had a $77.8 \%$ sensitivity and $71.4 \%$ specificity in predicting positive cases, with PPV $87.5 \%$ to predict positive cases\& NPV 55.6\%.

In this high risk group mean cord bilirubin was $2.52 \pm 0.80 \mathrm{mg} / \mathrm{dl}$. Our results are similar to those of Zeitoun et al who recorded that the mean cord bilirubin among high risk group is significantly higher compared to group with no risk [23]. However have a mean cord bilirubin of $1.84 \pm 0.45 \mathrm{mg} / \mathrm{dl}$, with no significant difference in the level of unconjugated bilirubin in cord blood between children with or without maternal-fetal blood incompatibility. Ipek et al. in 2012 recorded a mean cord bilirubin of $2.05 \pm 0.98 \mathrm{mg} /$ $\mathrm{dl}$.The difference between our results which shows a higher level and other studies may be due to higher percent of $\mathrm{ABO} \& \mathrm{RH}$ incompatibility cases in our study (33.3\%) than in others.

By using cord bilirubin - cord albumin to predict significant hyperbilirubinemia we found that a cut-off level of cord blood bilirubin-albumin of -0.82 as obtained by ROC curve was determined to have $88.9 \%$ sensitivity, $85.7 \%$ specificity \& PPV $94.1 \%$ in the prediction of occurrence of significant hyperbilirubinemia in high risk group, with NPV 75\%.

ROC curve shows that the area under the curve was 0.885 of total area; $\mathrm{p}$ value 0.003 indicating the usefulness of the test in predicting hyperbilirubinemia .

A cut off level of cord bilirubin/albumin ratio of 0.79 in our study was determined to have $83.3 \%$ sensitivity, $85.7 \%$ specificity and PPV 93.8\% in the prediction of occurrence of significant hyperbilirubinemia in high risk group, with NPV $66.7 \%$.

We conclude that the cut off level of bilirubin/albumin level in both total \& high risk group are more or less similar to each other ( $0.787 \& 0.797$ respectively). But the cut off value of high risk group had a higher sensitivity (83.3\%), specificity (85.7\%) and PPV (93.8\%) than that of total group.

We conclude from the results of our study ; that in the total group, the highest sensitivity (83.3\%) was for cut off value of cord bilirubin $(1.88 \mathrm{mg} / \mathrm{dl})$ with PPV $72.9 \%$, which mean that we can predict $83.3 \%$ of patients with the disease (true positives) but $16.7 \%$ of cases with the disease go undetected (false negatives); whilst the highest specificity (84.8\%) was for cut off value of cord bilirubin-albumin(-0.6)with NPV $74.1 \%$, which mean that we can correctly report $84.8 \%$ of patients without the disease as test negative (true negatives) but $15.2 \%$ patients without the disease are incorrectly identified as test positive (false positives).

bilirubin-albumin(-0.6)with NPV 74.1\%, which mean that we can correctly report $84.8 \%$ of patients without the disease as test negative (true negatives) but $15.2 \%$ patients without the disease are incorrectly identified as test positive (false positives).

We can use the bilirubin-albumin or bilirubin/albumin ratio to get the highest combination of bilirubin and albumin.

In high risk group, the highest sensitivity (88.9\%) highest PPV 94.1\%\& highest specificity (85.7\%) with NPV 75\%, is for cut off valueof cord bilirubin-albumin (-0.82).

Although the ideal (but unrealistic) situation is for a 100\% accurate test, a good alternative is to subject patients who are initially positive to a test with high sensitivity/low specificity, to a second test with low sensitivity/high specificity. In this way, nearly all of the false positives may be correctly identified as disease negative.

The highest PPV in both total (86.1\%) \& high risk group (94.1\%) is for cut off valueof cord bilirubin-albuminwhich is -0.6, -0.82 respectively. 
Our The present study included only late preterms \& full term babies ( $\geq 35$ wks)with no preterms $\leq 34$ wks included in our study which give no chance to test the predictive value of cord blood albumin \& bilirubin for development of significant hyperbilirubinemia in preterms in general. So further studies needed on preterms with a GA less than 35 weeks.

The current AAP guidelines (Pediatrics 2004) for managing healthy jaundiced term and near-term newborns recommend the use of the total bilirubin concentration(TBC)/albumin ratio in addition to the TBC. However a lower than expected albumin level at least alerts the physician to the possible need for intervention at lower than usual TSB levels.

It is important to recognize that sensitivity, specificity and predictive values are not intrinsic test characteristics, but depending on the studied population and therefore not necessary applicable outside this context in other populations.

The sensitivity of these tests with a NPV of $66.7 \%$ for cord bilirubin/albumin ratio is too low, so these parameters cannot be used for screening purposes because of the high number of false negatives.

Albumin is synthesized in the liver. It binds unconjugated bilirubin and helps in the transport. Low production of albumin probably caused by liver immaturity will lower its transport and binding capacity. Determination of CBA in at risk neonates will help to prevent the complications associated with $\mathrm{NH}$.

The combined result of $\mathrm{CBB}$, DAT (direct antiglobulin test) and ABO incompatibility analysis outperformed results of these parameters considered separately as reported by Peeters et al. (EUR. J. Ped 2016) [25].

CBA seems to be equivalent as $\mathrm{CBB}$ to predict non-hemolytic NH due to liver immaturity and mild ABO mediated hemolytic anemia. However, it is not proven that CBA is also a good predictor for severe HDFN due to maternal antibodies. Although NH associated with maternal antibodies are rare they can result in severe hyperbilirubinemia.

Neonatal physiologic jaundice results from simultaneous occurrence of the following two phenomena .[26].

- Bilirubin production is elevated because of increased breakdown of fetal erythrocytes. This is the result of the shortened lifespan of fetal erythrocytes and the higher erythrocyte mass in neonates [27,28].

- Hepatic excretory capacity is low both because of low concentrations of the binding protein ligandin in the hepatocytes and because of low activity of glucuronyl transferase, the enzyme responsible for binding bilirubin to glucuronic acid, thus making bilirubin water soluble (conjugation).

- Physiologic jaundice of the newborn is also referred to as neonatal hyperbilirubinemia and neonatal jaundice.

- Significant jaundice was defined according to gestational and postnatal age and leveled off at $14 \mathrm{mg} / \mathrm{dL}(240 \mu \mathrm{mol} / \mathrm{L})$ at $4 \mathrm{days}$ in preterm infants and $17 \mathrm{mg} / \mathrm{dL}(290 \mu \mathrm{mol} / \mathrm{L})$ in the term infants [29].

\section{Recommendations}

- Cord blood albumin \& bilirubin can be used as an early useful indicator to predict significant hyperbilirubinemia in neonates - Researches on large scale should be done for more clarification of the predictive value of cord blood albumin and bilirubin for early prediction of significant hyperbilirubinemia.

- The value of screening infants for jaundice before hospital discharge for risk assessment and in order to allow safe early discharge for the baby and to prevent readmission.

- Education to parents to provide early seeking of medical advice,

To minimize the high level of bilirubin seen on admission

\section{References}

1. Dennery PA, Seidman DS, Stevenson DK (2001) Neonatal hyperbilirubinemia. N Engl J Med 344: 581-90.

2. Bernaldo AJ, Segre CA (2004) Bilirubin dosage in cord blood: could it predict neonatal hyperbilirubinemia? Sao Paulo Med J 122: 5-19.

3. Rostami N, Mehrabi Y (2005) Identifying the newborn at risk for developing significant hyperbilirubinemia by measuring cord bilirubin levels. J Arab Neonatal forum 2: 81-5.

4. Robinson GC, Dunn HG, Wong LC (1960) Clinical and laboratory findings in heterospecific pregnancy, with a note on incidence of ABO hemolytic disease. Acta Pediatrica 49: 53-62.

5. Simpson L, Deoarari AK, Paul VK (2002) Cord bilirubin as a predictor of pathological jaundice-a cohort study. Indian Pediatrics 39: 724-30.

6. Rosenfeld J (1986) Umbilical cord bilirubin levels as a predictor of subsequent hyperbilirubinemia. J Fam Pract 23: 556-8.

7. Ghosh S, Ahmed SH, Kumari S, Bhargava SK (1971) Neonatal bilirubinemia and its relationship to long term neurological deficits. Indian pediatr 8: 704-6.

8. Trivedi DJ, Markande DM, Vidya BU, Bhat M, Hegde PR (2013) Int J Int sci Inn Tech Sec A 2: 39-42.

9. Akgül S, Korkmaz A, Yiğit S, Yurdakök M (2013) Neonatal hyperbilirubinemia due to ABO incompatibility: does blood group matter? Turk J Pediatr 55: 506-9. 
10. Venkatamurthy M, Murali SM, Hemachandra K (2014) Evaluation of cord serum albumin level as a risk indicator in predicting neonatal Jaundice. Int J Health Info Med Res 1: 9-11.

11. Iskander I, Gamaleldin R, El Houchi S, El Shenawy A, Seoud I, et al. (2014) Serum Bilirubin and Bilirubin/Albumin Ratio as Predictors of Bilirubin Encephalopathy. Pediatrics 134: e1330-9.

12. Lalkhen A, MB ChB FRCA, McCluskey A (2008) Clinical tests: sensitivity and Specificity. Continuing Education in Anaesthesia, Critical Care \& Pain 8: 221-3.

13. Jardine LA, Woodgate P (2011) Neonatal jaundice. BMJ Clin Evid 85: 824-5.

14. Cakmak A, Calik M, Atas A, Hirfanoglu I, Erel O (2008) Can haptoglobin be an indicator for the early diagnosis of neonatal jaundice? J Clin Lab Anal 22: 409-14.t

15. Iskander I, Gamaleldin R, Kabbani M (2012) Root causes for late presentation of severe neonatal hyperbilirubinaemia in Egypt. East Mediterr Health J 18: 882-7.

16. Zeitoun AA, Elhagrasy HF, Abdelsatar DM (2013) Egyptian Pediatric Association Gazette 61: 23-30.

17. Amer T, Vilhekar K, Jain M, Zade P, Atkari S, et al. (2005) Prediction of the development of neonatal hyperbilirubinemia by increased umbilical cord bilirubin. Curr Pediatr Res 9: 5-9.

18. Zoubir S, Mieth RA, Berrut S, Roth-Kleiner M, Swiss Paediatric (2011) Surveillance Unit: Incidence of severe hyperbilirubinaemia in Switzerland: a nationwide population-based prospective study. Arch Dis Child Fetal Neonatal Ed 96: F310-1.

19. Zakia N, Shahidukkah AM, Mannan A, Kumar S, Mitra U, et al. (2009) The value of umbilical cord blood bilirubin management in predicting the development of significant hyperbilirubinemia in healthy newborn. Bangladesh J Child Health 33: 50-9.

20. Satrya R, Effendi SH, Gurnida DA (2009) Correlation between cord blood bilirubin level and incidence of hyperbilirubinemia in term newborns. Paediatr Indones 49: 349-54.

21. Knüpfer M, Pulzer F, Gebauer C, Robel-Tillig E, Vogtmann C (2005) Predictive value of umbilical cord blood bilirubin for postnatal hyperbilirubinaemia. Acta Paediatr 94: 581-7.

22. Bernaldo A, Segre C (2004) Bilirubin dosage in cord blood: could it predict neonatal hyperbilirubinemia? Sao Paulo Med J 122: 5-19.

23. El-Gendy FM, Hassane FM, Khattab AA, El-Lahony DM, Ashour NM (2013) Predictive ability of first-day serum bilirubin and haptoglobin for subsequent significant hyperbilirubinemia in healthy-term and near-term newborn. Menoufia Med J 26: $127-31$.

24. Carbonell X, Botet F, Figueras J, Riu- Godó A (2001) Prediction of hyperbilirubinaemia in the healthy term newborn. Acta Paediatr 90: 166-70.

25. Wu JY, Peters JM, Goyal M, Krueger D, Sahin M, et al. (2016) Clinical Electroencephalographic Biomarker for Impending Epilepsy in Asymptomatic Tuberous Sclerosis Complex Infants. Pediatr Neurol 54: 29-34.

26. Huang MJ, Kua KE, Teng HC, Tang KS, Weng HW, et al. (2004) Risk factors for severe hyperbilirubinemia in neonates. Pediatr Res 56: 682-9.

27. Christensen RD, Yaish HM (2015) Hemolytic disorders causing severe neonatal hyperbilirubinemia. Clin Perinatol 42: 515-27.

28. Woodgate P, Jardine LA (2015) Neonatal jaundice: phototherapy. BMJ Clin Evid 2015: 0319.

29. Sahu S, Abraham R, John J, Mathew AA (2011) Cord blood albumin as a predictor of neonatal jaundice; IJBiomed Res 2: 436-8.

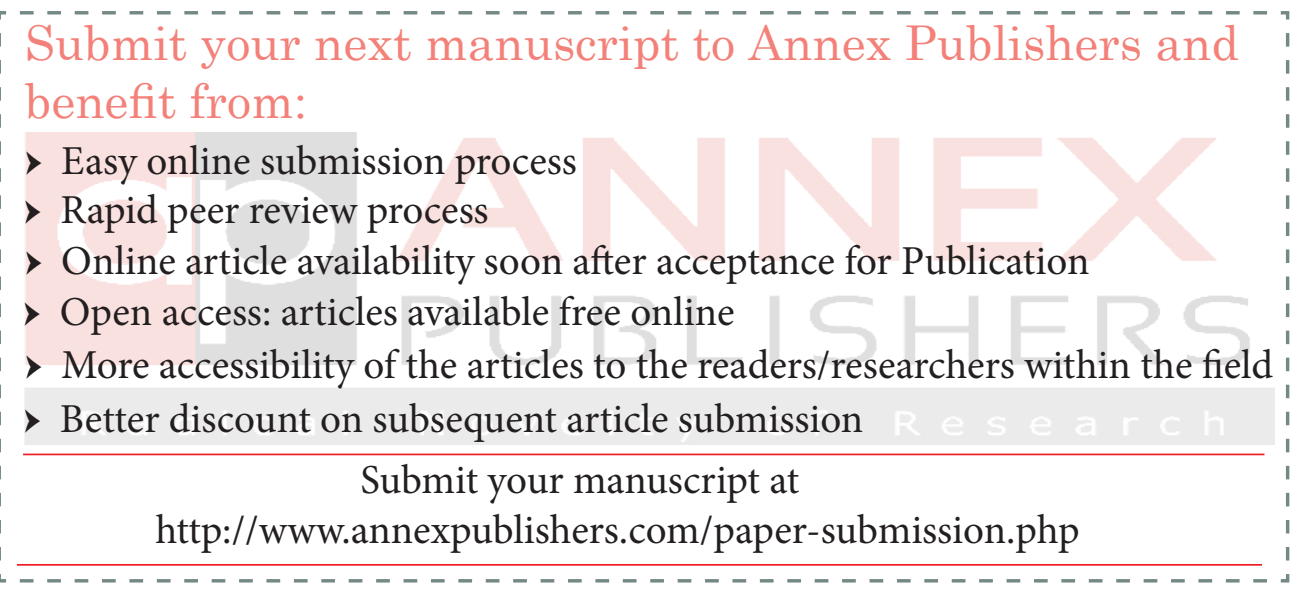

